\title{
INFLUÊNCIA DA GESTÃO FAMILIAR NA ESTRUTURA DE CAPITAL
}

INFLUENCE OF FAMILY MANAGEMENT IN THE CAPITAL STRUCTURE

Recebido em 23.02.2019. Aprovado em 03.05.2019

Avaliado pelo sistema double blind review

DOI: https://doi.org/10.12712/rpca.v13i2.28146

\section{Januário José Monteiro}

Januariomonteiromonteiro@gmail.com

Programa de Pós-Graduação em Contabilidade /Universidade Federal de Santa Catarina - Florianopolis/SC, Brasil

ORCID: https://orcid.org/0000-0002-7000-4256

\section{Valdirene Gasparetto}

valdirenegasparetto@gmail.com

Programa de Pós-Graduação em Contabilidade /Universidade Federal de Santa Catarina - Florianopolis/SC, Brasil

ORCID: http://orcid.org/0000-0002-2825-4067

\section{Rogério João Lunkes}

rogeriolunkes@hotmail.com

Programa de Pós-Graduação em Contabilidade /Universidade Federal de Santa Catarina - Florianopolis/SC, Brasil

ORCID: https://orcid.org/0000-0003-4232-5746

\section{Resumo}

O presente estudo teve por objetivo examinar a influência da estrutura de gestão familiar na estrutura de capital. Para sua operacionalização foram selecionadas empresas brasileiras listadas na B3 durante o período de 2013 a 2017, que totalizou em 266 empresas não financeira. Coletou-se os dados no formulário de referências e na base de dados Economatica. O método estatístico usado foi regressão em painel. Os achados evidenciam que empresas com estrutura de gestão familiar exercem influência sobre o endividamento de curto prazo. Quanto ao endividamento total e de longo prazo não se observou associação significativa com a estrutura de gestão familiar.

Palavras-chave: Estrutura de gestão familiar; Estrutura de capital; Empresa familiar.

\begin{abstract}
The present study aimed to examine the influence of the family management structure on the capital structure. For its operation were selected Brazilian companies listed in B3 during the period from 2013 to 2017, which was 266 non-financial companies. The data was collected in the reference form and in the Economatica database. The statistical method used was panel regression. The findings show that companies with a family management structure exert influence over short-term indebtedness. Regarding total and long-term indebtedness, there was no significant association with the family management structure
\end{abstract}

Keywords: Family management structure; Capital structure; Family business. 


\section{Introdução}

O modelo de organização caracterizado como empresa familiar tem desempenhado um papel importante na economia global (BIRD et al., 2002). Essas entidades apresentam características próprias e se comportam de maneira diferente em relação a outros modelos de organização (Habbershon; Williams, 1999; Sirmon; Hitt, 2003; Carney et al. 2015). Atualmente, esse modelo de organização existe em todo mundo e predomina em diferentes contextos (Claessens et al.,2002; Faccio; Lang, 2002; Anderson; Reeber,2003; Chen et al., 2008; Prencipe et al., 2014; DE Massis et al., 2018). Apesar disso, e de ter sido objeto de estudo de várias pesquisas, não há uma definição padrão, o que se dá principalmente pelo contexto histórico, econômico e sócio-político dos diferentes países dos quais as empresas familiares foram objeto de estudo (HERNÁNDEZ-LINARES, SARKAR, E COBO 2018).

Neste estudo se tomará por bases a pesquisa de Villalonga e Amit (2006) e Perez-Gonzalez (2006), e de maneira específica o estudo de Miller et al. (2007), que apresentam 28 definições de empresa familiar, os autores definem empresas familairas como aquelas em que vários membros da mesma família estão envovidos na gestão e que um ou mais membro é proprietário de pelo menos uma parte do capital.

Segundo Family Firm Institute (FFI, 2018) empresas familiares constituem 2/3 das empresas no mundo e estima-se que são responsáveis por 70\% a 90\% do PIB global; são geradoras de $50 \%$ a $80 \%$ dos empregos em todo mundo e $85 \%$ das empresas start-up são estabelecidas com capital familiar. De acordo o FFI, 50\% do PIB brasileiro é criado por empresas familiares e geram cerca de $85 \%$ dos empregos em todo Brasil.

Diante dessa representatividade, Pamplona, Dal Magro e Silva (2017) afirmam que estudos que tratam da estrutura de capital e desempenho econômico em empresas familiares são essenciais para se perceber o funcionamento deste tipo de organização. Mishra e McConaughy (1999) apontaram que empresas familiares normalmente apresentam maior aversão ao risco, pois tendem a evitar endividamento, com receio de perderem o controle e a posição dominante da família na gestão (PRENCIPE e COLS, 2008; GONZÁLEZ et al., 2013; YOUSAF; HASSAN,2016).

Segura e Formigoni (2014) sugeriram pesquisas futuras que tratassem da relação ente Gestão familiar e a Estrutura de capital, diante desse cenário surge a questão norteadora desta pesquisa: Qual a influência da estrutura de gestão familiar (propriedade, controle e gestão familiar) na estrutura de capital das empresas brasileiras de capital aberto? O objetivo desse estudo consiste em examinar a influência da estrutura de gestão familiar (propriedade familiar, controle familiar e gestão familiar) na estrutura de capital (endividamento de curto prazo, longo prazo e total).

Pamplona, Dal Magro e Silva (2017) identificaram a influência da estrutura de capital no desempenho econômico das empresas familiares do Brasil e de Portugal. A amostra foi composta por 73 empresas familiares brasileiras e 18 portuguesas coletadas durante o período de 2009 a 2013. Os resultados demonstraram que nas empresas familiares brasileiras quando o índice de endividamento é maior, melhor é o desempenho, enquanto nas portuguesas quanto maior o capital próprio melhor o desempenho.

Segura e Formigoni (2014) investigaram a influência da família no endividamento das empresas brasileiras. A amostra foi de 365 empresas durante o período de 2004 a 2009. Os resultados demonstraram que não há associação entre o controle familiar e o endividamento, no entanto, quanto à gestão familiar observaram a existência de associação com o endividamento.

O presente estudo se diferencia dos demais pois, busca verificar a influência da propriedade (ownership), do controle e da gestão familiar, três elementos que formam a estrutura de gestão familiar, contemplados na definição de empresa familiar (Sonfield e Lussier, 2012), na estrutura de capital em um período mais recente (2013 a 2017). 
Além disso, diversos estudos sobre empresas familiares têm sido desenvolvidos no Brasil, no entanto, faltam estudos que relacionem a gestão de membros da mesma família e a estrutura de capital das empresas (Segura e Formigoni, 2014). No mais, não se observa unanimidade na literatura sobre este tema (Hernández-Linares, Sarkar, e Cobo 2018), assim o estudo se justifica por contribuir com a literatura no que concerne à relação entre a estrutura de gestão familiar e o endividamento das empresas.

Em complemento Prencipe, Bar-Yosef e Dekker (2014) constaram que as pesquisas sobre empresas familiares na área de gestão, representam apenas $22 \%$, no entanto em relação à área financeira a representatividade é maior ( $60 \%$ ) logo, esta pesquisa se propõe contribui sob as duas perspectiva, primeiro ao investigar a estrutura de gestão familiar que compreende a gestão das mesma, e ao verificar a estrutura de capital que está relacionado as finanças das empresas familiares brasileiras.

Percebe-se que empresas familiares são relevantes para a economia global e por isso estudos que buscam entender como e porquê se comportam de determinada maneira são relevantes e contribuem não somente no campo teórico, propiciando subsídios para a comunidade acadêmica, mas também no âmbito prático e social, à medida em que o conhecimento gerado contribui no melhor entendimento desse modelo de organização, ajudando os tomadores de decisão a serem mais assertivos, o que agregará para a sociedade em geral, já que maior parte do PIB global é gerado por empresas familiares.

O presente estudo está subdividido em 4 sessões, sendo a primeira a presente introdução, seguida do referencial teórico, metodologia e análise dos resultados, considerações finais e referências.

\section{Referencial Teórico}

A presente seção trata dos diversos entendimentos sobre empresas familiares, a estrutura de capital segundo as teorias de trade-off e packing order e estudos que relacionaram a estrutura de gestão familiar e a estrutura de capital.

\section{Empresas familiares}

Desde a época das civilizações ocidentais, as atividades econômicas na Grécia se centravam majoritariamente em negócios familiares, estas circunstâncias não se alteraram significativamente no império Romano nem nos períodos sucessivos de descoberta da idade média e do novo mundo (BIRD et al., 2002).

Apesar de sua existência e funcionamento ser antiga, somente na década de 1990 a temática "empresa familiar" passou a ser vista como disciplina acadêmica, sendo que os primeiros estudos visavam analisar os subsistemas família e gestão (HANDLER,1989; GRERSICK; DAVIS; HAMPTON; LANBERG, 1997; BIRD et al., 2002).

Atualmente, empresas familiares continuam sendo um diferencial para economia global, pois representam $2 / 3$ do total de empresas no mundo e são responsáveis pela criação de $70 \%$ a $90 \%$ do PIB mundial (ASTRACHAN; SHANKER, 2003; DENIIS, 2003; KELLERMANNS ET AL., 2008; FAMILY FIRM INSTITUTE, 2018).

Embora esta temática seja um campo de estudo relativamente recente (Bhalla et al., 2006), tem demonstrado evolução, pois há um crescente interesse de pesquisadores e principais meios de publicação de estudos sobre empreendedorismo, gestão e também na disseminação de conhecimentos sobre a temática no tocante às suas caraterísticas, comportamento e importância para economia global (CHRISMAN et al., 2008; BENAVIDES-VALASCO, QUINTANA-GARCÍA, GUZMÁNPARRA,2013); XI et al., 2015).

Benavides-Valasco, Quintana-García e Guzmán-Parra (2013) buscaram descrever as tendências das pesquisas sobre empresas familiares. Por meio da análise bibliométrica durante o período de 1961 a 
2008, obtiveram 703 artigos e concluíram que: (i) estes estudos se encontram em constante evolução, (ii) o periódico mais proeminente foi o Family business Review com 417 publicação, (iii) os Estados Unidos foi o país que mais publicou, (iv) o tema mais difundido foi "sucessão familiar", e (v) obvervaram que se deveria entender com maior especificidadade as principais diferenças entre empresas familiares e não familiares, ou seja, saber o porquê e como esta forma de organização se comporta.

De acordo Pieper e Klein (2007), estudos sobre empresa familiar evoluíram e passaram a apresentar um corpo conceitual estruturado, no entando várias são as definções sobre empresa familiar o que presupõe não haver consenso (SONFIELD;LUSSIER, 2012; RAMALHO; RITA; SILVA 2018). Desse modo, não se tem uma definição padrão sobre este tipo de organização, assim são apresentados no quadro 1 os vários entendimentos sobre a definição e caraterização de empresa familiar.

Quadro 1- Definição e caracterização de empresa familiar

\begin{tabular}{|c|c|}
\hline Definição de empresa familiar & Referência \\
\hline Empresa em que o CEO é o fundador ou membro da família fundadora & Mc Conaughyetal et al. (1998) \\
\hline $\begin{array}{l}\text { Membro da família com pelo menos } 10 \% \text { das ações; membros da família no conselho } \\
\text { de administração; mais de } 50 \% \text { dos acentos no conselho ocupados por membros da } \\
\text { mesma família. }\end{array}$ & $\begin{array}{c}\text { Mok, Lam e Cheung } \\
\text { (1992); Morck e Yeung (2004) e } \\
\text { shyu (2011) }\end{array}$ \\
\hline Qualquer empresa dirigida por um fundador ou vários membros da família fundadora. & $\begin{array}{l}\text { Shanker e Astrachan, (1996); } \\
\quad \text { Lansberg,(1999) }\end{array}$ \\
\hline Se pelo menos 33\% das ações for de um único acionista ou de uma família. & Barth et al. (1996) \\
\hline $\begin{array}{l}\text { Geralmente empresa controlada por uma família ou que na gestão apresenta vários } \\
\text { membros da família é caracterizada como empresa familiar. }\end{array}$ & $\begin{array}{l}\text { (Shanker; Astrachan, 1996; } \\
\text { Lansberg, 1999) }\end{array}$ \\
\hline $\begin{array}{l}\text { Considera-se quando uma pessoa ou grupo familiar possui pelo menos } 10 \% \text { do poder } \\
\text { de voto. }\end{array}$ & Smith e Amoako-Adu (1999) \\
\hline $\begin{array}{l}\text { Se dois ou mais diretores forem membros da mesma família e se possuírem pelo menos } \\
5 \% \text { dos votos na assembleia. }\end{array}$ & Gomez-Mejia et al. (2003) \\
\hline $\begin{array}{l}\text { Aquela que possui pelo menos } 10 \% \text { de participação acionária e tem poder de decisão } \\
\text { acima de } 51 \% \text {. }\end{array}$ & Barontini e Caprio (2006) \\
\hline $\begin{array}{l}\text { Se o shareholder obtiver pelo menos } 10 \% \text { dos direitos ao voto e for membro da família } \\
\text { fundadora ou fundador do maior grupo controlador. }\end{array}$ & Maury (2006) \\
\hline $\begin{array}{l}\text { Considera-se quando o fundador ou um membro da família for detentor de pelo menos } \\
5 \% \text { do patrimônio da empresa e tiverem poder considerável nas decisões; um ou mais } \\
\text { membros da família forem diretores; um ou mais membro da família de segunda } \\
\text { geração ou para mais, forem membros diretores ou membros efetivos na assembleia. }\end{array}$ & Villalonga e Amit (2006) \\
\hline $\begin{array}{l}\text { Caso o fundador possuir pelo menos } 5 \% \text { do capital e for executivo ou diretor com } \\
\text { poder de decisão }\end{array}$ & Perez-Gonzalez (2006) \\
\hline
\end{tabular}

Fonte: adaptado pelos autores (2018) 
Percebe-se, diante dessa variedade de definições, que o enfoque principal está no grau de propriedade do capital pela família, o controle acionário e envolvimento da família na gestão (SONFIELD; LUSSIER, 2012). Miller et al. (2007) identificaram 28 definições sobre empresa familiar e mediante comparação, elaboram uma definição que envolvesse o grau de propriedade do capital, participação acionário e envolvimento da família na gestão. Os autores definiram empresa familiar como sendo aquela em que vários membros da mesma família estão envovidos na gestão ou que um ou mais membros é proprietário de pelo menos uma parte do capital.

\section{Estrutura de capital}

Ao se tratar de estudos sobre estrutura de capital geralmente a teoria trade-off e pecking order são abordados. A teoria trade-off derivou dos estudos de Modigliani e Miller (1958) e seu princípio central é que empresas estabelecem um nível alvo na relação entre o endividamento e o capital no intuito de equilibrar os benefícios fiscais da dívida e o custo de financiamento das dívidas. A teoria pecking order surgiu em 1980 desenvolvida por Myers e Majluf (1984) e se fundamenta na ideia de que as empresas tendem hierarquizar as fontes se financiamento. Inicialmente usam recursos próprios e em seguida financiamento externo, ou seja, captação de capital de terceiros e, na impossibilidade dessas hipóteses, a empresa emite ações no mercado. Ao tratar de empresas familiares, Blanco-Mazagatos et al. (2007) afirmam que estas tendem a ser mais conservadoras e procuram menos financiamento externo para impedir a diluição do controle familiar e não comprometer as futuras gerações.

Ampenberger et al. (2013) buscaram entender como a gestão familiar impacta nas decisões sobre a estrutura de capital. Mediante análise de 660 empresas listadas na bolsa alemã durante o período de 1995 a 2006, concluíram que empresas familiares têm o índice de alavancagem significativamente mais baixo do que as empresas não familiares e quando o CEO é fundador a tendência é que o nível de endividamento tenha efeito negativo.

Yousaf e Hassan (2016) examinaram o efeito do controle familiar sobre a decisão de financiamento das empresas paquistanesas. A amostra foi de 100 empresas não financeiras listadas na bolsa de valores de Karachi durante o período de 2005 a 2012. Os resultados demonstram que empresas familiares apresentam grau de endividamento significativamente elevado em relação às não familiares. Os autores justificam que as empresas familiares são mais resistentes e normalmente não diluem o capital, por isso buscam financiamento de terceiros para honrar com seus compromissos, ao invés de emitirem novas ações e extraírem financiamento do mercado, por outro lado acrescentam que empresas familiares no Paquistão usam recursos próprios para benefício dos proprietários.

Diéguez-Soto e Lópes-Delgado (2018) avaliaram se o envolvimento da família impacta na alavancagem das empresas. A amostra foi de 4102 empresas espanholas durante o período de 2006 a 2013 e o método aplicado foi regressão em painel. Os achados evidenciam que o envolvimento da família influencia nas decisões tomadas sobre a estrutura de capital, e que quanto mais envolvimento da família menor o endividamento.

Ramalho Rita e Silva (2018) investigaram a influência da propriedade familiar na alavancagem de empresas familiares e não familiares e examinaram a influência do tamanho da empresa, localização geográfica e a crise financeira global de 2008 na estrutura de capital de empresas familiares. Foram selecionadas 9220 empresas portuguesas durante o período de 2006 a 2012. Os achados demonstraram que empresas familiares se endividam menos, contudo, em período de crise são mais propensas ao endividamento. Observaram ainda que a proporção do endividamento das empresas familiares de grande porte tende a aumentar mais do que das de pequeno porte. 
De acordo a literatura apresentada elaborou-se as seguintes hipóteses:

H1a- A estrutura de gestão familiar exerce influência no endividamento de curto prazo.

H1b- A estrutura de gestão familiar exerce influência no endividamento de longo prazo.

H1c-A estrutura de gestão familiar exerce influência no endividamento total.

\section{Procedimentos metodológicos}

Nessa seção são apresentados os procedimentos metodológicos percorridos para a execução da pesquisa, bem como a coleta e análise dos resultados.

\section{Enquadramento metodológico}

O presente estudo se caracteriza como descritivo, pois examina a influência da propriedade, controle e gestão familiar na estrutura de capital. De acordo Martins Jr. (2008), pesquisas descritivas são utilizadas para descrever fenômenos sociais, de modo a compreendê-los. Quantos aos procedimentos a pesquisa é bibliográfica, tendo em vista que foi realizada levantamento da literatura (GIL, 2002).

Em relação à coleta de dados a pesquisa é documental, pois foram utilizados dados dos CEO (Chief Executive Officer), administradores e diretores por meio do formulário de referências da B3. No tocante à abordagem o estudo é quantitativo por recorrer a técnicas estatísticas como análise de dados em painel desbalanceado (RICHARDSON, 2017).

Para considerar a população desse estudo foram observados o conjunto de empresas que se encontravam ativas em 2017, sendo 367 empresas dentre as quais se encontram as financeiras e não financeiras.

$\mathrm{Na}$ sequência, foram excluídas da população empresas financeiras por apresentarem uma estrutura de endividamento peculiar e outras empresas que embora fossem não financeiras, não apresentaram dados contábeis suficientes para análise, desse modo a amostra final foi de 266 empresas durante o período de 2013 a 2017.

Os dados financeiros foram extraídos da Economatica e as informações referentes aos dados dos cinco maiores acionistas, CEOs presidentes do conselho de administração, diretores financeiros, acionistas direto e indireto, foram obtidos do formulário de referência da B3 nos itens 1-Responsáveis pelo formulário, 12- Assembleia e administração, 12.5/6- Composição e experiência profissional da administração e do CFO (Chief Financial Officer) e 12.9-Relações familiares.

Desse modo foram selecionadas as empresas de acordo com o setor, conforme pode-se observar na Tabela 1. 
Januário José Monteiro, Valdirene Gasparetto e Rogério João Lunkes

Tabela 1- Distribuição das empresas por setor

\begin{tabular}{|c|c|c|}
\hline Setores & Número de Empresas & Percentagem \\
\hline Agropecuária & 6 & $2 \%$ \\
\hline Água e Saneamento & 5 & $2 \%$ \\
\hline Alimentos Processados & 12 & $5 \%$ \\
\hline Automóveis e Motocicletas & 3 & $1 \%$ \\
\hline Comércio & 15 & $6 \%$ \\
\hline Comércio e Distribuição & 7 & $3 \%$ \\
\hline Computadores e Equipamentos & 2 & $1 \%$ \\
\hline Construção Civil & 19 & $7 \%$ \\
\hline Construção e Engenharia & 8 & $3 \%$ \\
\hline Diversos & 14 & $5 \%$ \\
\hline Energia Elétrica & 35 & $13 \%$ \\
\hline Gás & 2 & $1 \%$ \\
\hline Hotéis e Restaurantes & 4 & $2 \%$ \\
\hline Madeira e Papel & 7 & $3 \%$ \\
\hline Máquinas e Equipamentos & 12 & $5 \%$ \\
\hline Material de Transporte & 8 & $3 \%$ \\
\hline Medicamentos e Outros Produtos & 4 & $2 \%$ \\
\hline Mineração & 4 & $2 \%$ \\
\hline Petróleo, Gás e Biocombustíveis & 11 & $4 \%$ \\
\hline Produtos de Uso Pessoal e de Limpeza & 2 & $1 \%$ \\
\hline Programas e Serviços & 5 & $2 \%$ \\
\hline Químicos & 6 & $2 \%$ \\
\hline Serviços & 6 & $2 \%$ \\
\hline $\begin{array}{l}\text { Serviços médicos Hospitalares- Análises e } \\
\text { Diagnósticos }\end{array}$ & 9 & $3 \%$ \\
\hline Siderurgia e Metalurgia & 10 & $4 \%$ \\
\hline Tecidos, Vestuário e Calçados & 18 & $7 \%$ \\
\hline Telecomunicações & 4 & $2 \%$ \\
\hline Transporte & 17 & $6 \%$ \\
\hline Utilidades Domésticas & 4 & $2 \%$ \\
\hline Viagens e Lazer & 7 & $3 \%$ \\
\hline TOTAL & 266 & $100 \%$ \\
\hline
\end{tabular}

Fonte: dados da pesquisa (2018)

Após selecionadas as empresas para o estudo, verificou-se o grau de relação familiar entre os diretores e o presidente do conselho de administração, $\mathrm{CEO}$, em alguns casos $\mathrm{CFO}$ e os acionistas. O estudo considerou os graus de parentesco até a terceira geração, conforme proposição de Villalonga e Amit (2006).

A pesquisa tomou como base as ponderações de Perez-Gonzalez (2006), que considerou como empresa familiar aquelas que apresentavam as seguintes características: (i) um dos membros possui pelo menos $5 \%$ da propriedade do capital da empresa caso as ações sejam pulverizadas e $10 \%$ a $20 \%$ caso o controle seja mais concentrado; (ii) o fundador seja um executivo ou diretor com poder de decisão; e (iii) dois ou mais membros com mesmo grau sanguíneo (até o terceiro grau) sejam diretores ou shareholder ou possuam algum cargo de gestão. 
De acordo as observações feitas nas 266 empresas selecionadas para o estudo, 38\% foram classificadas como empresas familiares, por apresentarem características típicas deste tipo de entidade, ou seja, pelo menos dois membros da mesma família detendo no mínimo $5 \%$ do patrimônio da empresa e/ou com poder considerável nas decisões ou membro diretor que participa da gestão ou, ainda, membro efetivo na assembleia com poder de voto (Perez-Gonzalez, 2006; Villalonga e Amit, 2006). Essas constatações se aproximam aos achados de Segura e Formigoni (2014) quando observaram que 30\% das empresas brasileiras listadas na Bovespa no período de 2004 a 2009 eram empresas familiares.

Constata-se ainda que os setores mais representativos foram: Energia elétrica com 13\%, setor têxtil e construção civil com 7\% cada e comércio e transportes com $6 \%$ cada.

Para melhor compreensão apresenta-se a Figura 1, com o libby box da pesquisa.

Figura 1. Libby box da pesquisa

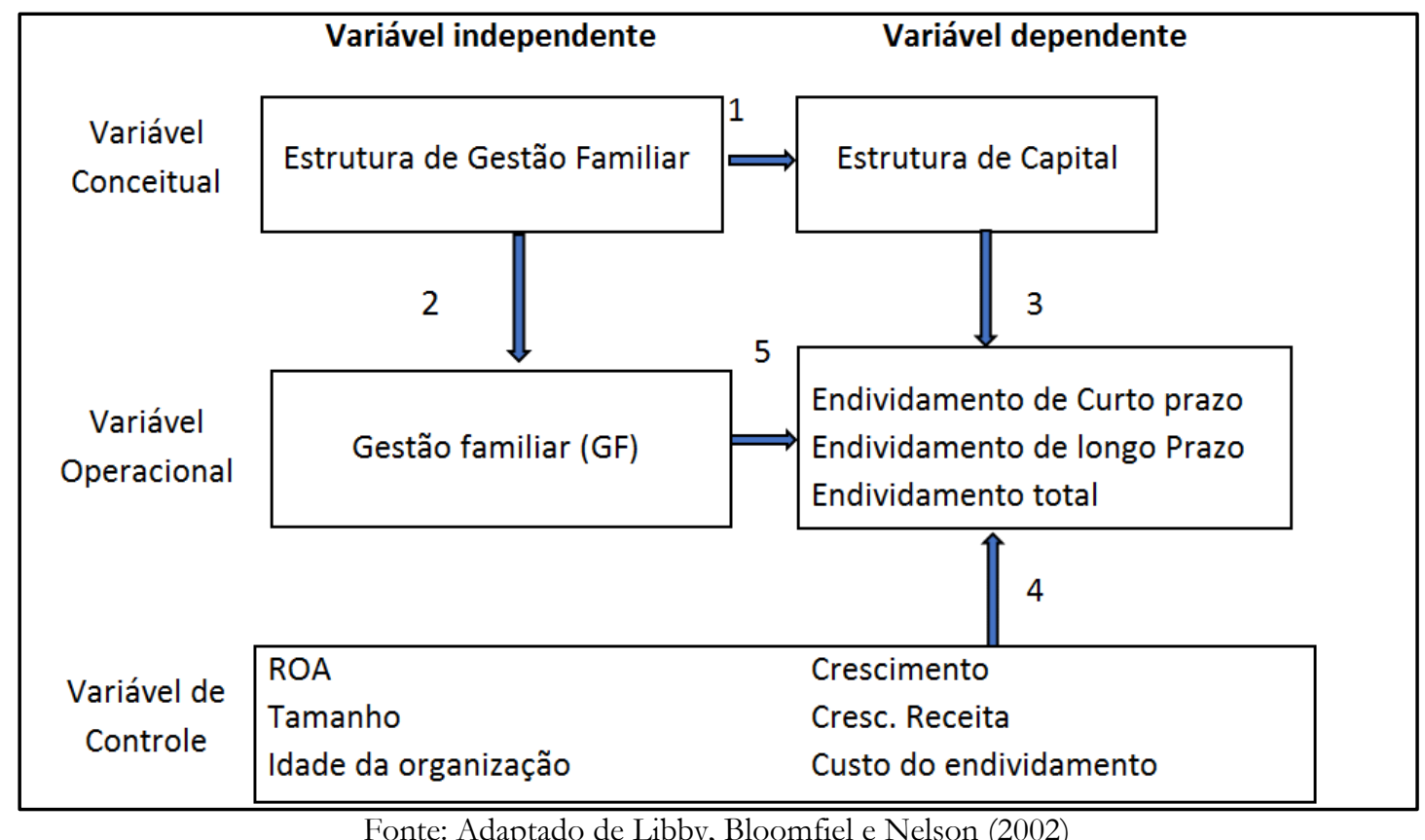

No libby box é apresentado no primeiro nível (legenda 1) as variáveis conceituais que evidenciam a vaidade externa; na legenda (2 e 3) a validade do constructo; na legenda (4) a validade interna e na legenda (5) a validade estatística.

As variáveis apresentadas neste estudo tiveram como base outros estudos que abordaram a estrutura de capital em empresas familiares, como por exemplo Soares e Kloeckner (2008); Ampenberger et al. (2013), Segura e Formigoni (2014), Dal Magro e Da Silva (2017), Molly et al. (2018). 
Quadro 2 - Apresentação e definição das variáveis do estudo

\begin{tabular}{|c|c|c|c|}
\hline Variáveis & Equação & Definição operacional & Referência \\
\hline \multicolumn{4}{|c|}{ Dependentes } \\
\hline $\begin{array}{l}\text { Endividamento de C. P- } \\
\text { (ECP) }\end{array}$ & $\mathrm{PC} / \mathrm{AT}$ & $\begin{array}{l}\text { A razão entre o passivo de curto } \\
\text { prazo e o ativo total }\end{array}$ & Sheikh e Wang (2011) \\
\hline $\begin{array}{l}\text { Endividamento de LP } \\
\text { (ELP) }\end{array}$ & $\mathrm{PNC} / \mathrm{AT}$ & $\begin{array}{l}\text { A relação entre as obrigações de } \\
\text { longo prazo e o ativo total }\end{array}$ & Ramanda (2013) \\
\hline Endividamento Total (ET) & $\mathrm{PC}+\mathrm{PNC} / \mathrm{AT}$ & $\begin{array}{l}\text { A razão entre as dívidas totais e os } \\
\text { ativos totais }\end{array}$ & Salim e Yavad (2012) \\
\hline \multicolumn{4}{|c|}{ Independentes } \\
\hline \multirow{3}{*}{$\begin{array}{l}\text { Estrutura de gestão familiar } \\
\text { (Empresa familiar) - (GF) }\end{array}$} & \multirow{3}{*}{$\begin{array}{l}\text { Dummy se } \operatorname{sim} 1 \\
\text { contrario- } 0\end{array}$} & $\begin{array}{l}\text { Se dois ou mais membros com } \\
\text { mesmo grau sanguíneo (até o terceiro } \\
\text { grau) forem diretores ou shareholder ou } \\
\text { possuírem algum cargo de gestão. }\end{array}$ & \multirow{3}{*}{\begin{tabular}{|l} 
Perez-Gonzalez \\
$(2006)$ \\
\\
\end{tabular}} \\
\hline & & $\begin{array}{l}\text { Se o fundador for um executivo ou } \\
\text { diretor com poder de decisão. }\end{array}$ & \\
\hline & & $\begin{array}{l}\text { Um dos membros possui pelo menos } \\
5 \% \text { da propriedade do capital da } \\
\text { empresa caso as ações forem } \\
\text { pulverizadas e caso não forem } \\
\text { considera-se entre } 10 \% \text { a } 20 \% \text { caso } \\
\text { forem menos concentradas }\end{array}$ & \\
\hline \multicolumn{4}{|c|}{ Variável de Controle } \\
\hline Tamanho (TM) & $\operatorname{Ln}(\mathrm{At})$ & Logaritmo natural do total do ativo & $\begin{array}{l}\text { Soares e Kloeckner } \\
(2008)\end{array}$ \\
\hline Idade & Ln (idade) & \begin{tabular}{|l}
$\begin{array}{l}\text { Logaritmo natural da idade da } \\
\text { organização }\end{array}$ \\
\end{tabular} & $\begin{array}{l}\text { Soares e Kloeckner } \\
(2008)\end{array}$ \\
\hline $\begin{array}{l}\text { Custo do endividamento } \\
\text { (CUSTO_ENDIV) }\end{array}$ & $\begin{array}{l}\text { Juros/endividamento } \\
\text { total }\end{array}$ & $\begin{array}{l}\text { Despesas com juros em relação } \\
\text { endividamento total. }\end{array}$ & Vieira (2016) \\
\hline Crescimento (CRESC) & Ati,t / Ati,t-1. & $\begin{array}{l}\text { Ativo total ano } \mathrm{N} \text { dividido pelo ativo } \\
\text { total do ano } \mathrm{N}-1 \text {. }\end{array}$ & $\begin{array}{l}\text { Soares e Kloeckner } \\
(2008)\end{array}$ \\
\hline $\begin{array}{l}\text { Crescimento } \quad \text { Vendas } \\
\text { (CRESC_RECEITA) }\end{array}$ & $\mathrm{RLV} / \mathrm{RLVt}-1$ & $\begin{array}{l}\text { Receita liquida de venda do ano } \mathrm{N} \text { em } \\
\text { relação a receita liquida do ano } \mathrm{N}-1 \text {. }\end{array}$ & Brito et al. (2007) \\
\hline ROA & At/PL & Ativo total sobre patrimônio líquido & $\begin{array}{l}\text { Anderson e Reeb } \\
(2003)\end{array}$ \\
\hline
\end{tabular}

Fonte: Adaptado pelos autores (2018)

\section{Apresentação e análise dos resultados}

Inicialmente efetuou-se teste de correlação para verificar se existe multicolineridade no modelo. Em momento posterior foi realizado o teste "Breusch and pagan" para verificar qual o método mais ajustado aos dados, tendo resultado em Prob $>$ chibar2 $=0.0000$, demonstrando que os efeitos aleatórios melhor se adaptam ao modelo.

$\mathrm{Na}$ sequência, foi efetuado o teste $\mathrm{F}$ de chow e resultou em uma probabilidade inferior a $5 \%$, desse modo foi de Prob $>$ chibar $2=0.0000$, evidenciando que o efeito fixo melhor se adapta ao modelo. Diante do observado houve a necessidade de efetuar o teste de Hausman com a finalidade de verificar se os estimadores são similares (efeitos aleatórios) ou divergentes (efeitos fixos), assim se constatou que os efeitos são fixos, pois a probabilidade foi inferior a $5 \%$ conforme resultado, Prob $>$ chi $2=0.0003$. Esses procedimentos são concordes com Favero e Belfiore (2014), dado que consideram esses, os procedimentos básicos e essenciais para o modelo de regressão em painéis. 
Constatado que os efeitos fixos melhor se encaixam ao modelo, foi efetuada regressão em painel para cada constructo levantado nas hipóteses, desse modo é apresentado conforme a Tabela 2, regressão e análise do endividamento a curto prazo.

Tabela 2- Fatores associados ao endividamento de curto prazo

\begin{tabular}{|c|c|c|c|c|}
\hline Variáveis & Coeficiente & Erro padrão & Valor $\mathrm{t}$ & Valor $\mathrm{p}$ \\
\hline GF & 0.140 & 0.088 & 1.59 & $0.10^{*}$ \\
\hline TM & -0.654 & 0.316 & -2.07 & $0.04^{* *}$ \\
\hline CUSTO_ENDIV & -0.108 & 0.120 & -0.90 & 0.37 \\
\hline CRESC & -0.117 & 0.068 & -1.71 & $0.09 *$ \\
\hline CRESC_RECEITA & -0.001 & 0.001 & -0.50 & 0.62 \\
\hline IDADE & -0.660 & 0.250 & -2.64 & $0.01 * *$ \\
\hline ROA & -0.003 & 0.002 & -1.41 & 0.16 \\
\hline Constante & 5.332 & 2.267 & 2.35 & $0.02 * *$ \\
\hline sigma_u & 0.637 & \multicolumn{2}{|c|}{ R2 Ajustado - within } & 0.09 \\
\hline sigma_e & 0.282 & \multirow{2}{*}{\multicolumn{2}{|c|}{$\begin{array}{l}\text { R2 Ajustado -between } \\
\text { R2 Ajustado -overall }\end{array}$}} & 0.03 \\
\hline rho & 0.836 & & & 0.03 \\
\hline & & \multicolumn{2}{|c|}{ Valor da estatística F } & 0.000 \\
\hline
\end{tabular}

*significância ao nível de $10 \%$; ** significância ao nível de 5\%, e; ***significância ao nível de 1\%. As regressões foram estimadas a partir da técnica GLS. O modelo foi fundamentado a partir da seguinte equação:

$E C P_{i t}=\beta_{0}+\beta_{l} G F_{i t}+\beta_{2 T} T M_{i t}+\beta_{3} C U S T O \_E N D I V_{i t}+\beta_{4} C R E S C_{i t}+\beta_{5} C R E S C \_R E C E I T A_{i t}+\beta_{6} I D A D E_{i t}+\beta_{72 O A_{i t}}+$

Eit

Observa-se que o modelo proposto é válido pois o valor da estatística $\mathrm{F}$ é de 0,000 , constata-se ainda que quando usada a variável de Endividamento de Curto Prazo (ECP) o R-quadrado foi de 0,09 demonstrando que as variáveis independentes e de controle explicam $9 \%$ do endividamento de curto prazo das empresas familiares. Para Cohen (1988) em ciências sociais aplicada este índice é considerado médio.

A variável tamanho (TM) é significativa ao nível de 5\% demonstrando que quanto menor o tamanho menor o endividamento de curto prazo das empresas com estrutura de gestão familiar; a variável Crescimento (CRESC) mostra-se significativa ao nível de $10 \%$, evidenciando que quanto menor a variação dos ativos, menor o endividamento de curto prazo. Essas evidenciam permitem aduzir que empresas familiares com uma estrutura relativamente pequena, são cautelosas quanto à obtenção de financiamentos de curto prazo. Esses achados em parte se assemelham aos de Ampenberger et al. (2013) tendo em vista que constataram efeito negativo no endividamento. $\mathrm{Na}$ mesma linha esta pesquisa corrobora com Ramalho Rita e Silva (2018) dado que observaram que quando o porte da empresa familiar é maior o endividamento tende a aumentar.

Quanto à variável IDADE, observou-se alto nível de significância de 1\% evidenciando que quanto menor a idade da organização, menor o endividamento de curto prazo das empresas familiares. Esse achado é congruente com o cotidiano organizacional brasileiro tendo em vista que, geralmente em fase inicial as empresas têm poucas oportunidades de efetivar empréstimo. Ao nível de $10 \%$ de significância foi encontrada associação positiva entre a estrutura de Gestão Familiar (GF) e o endividamento de curto prazo, desse modo é possível inferir que as empresas que possuem gestão familiar apresentam estrutura de capital de curto prazo maior do que as que não possuem gestão familiar, ou seja, exercem influência sobre as decisões de obtenção de capital de terceiros de curto prazo. Esses achados corroboram com Acedo-Ramírez, Ayala-Calvo e Navarrete-Martínez (2017) que investigaram se a estrutura de capital das empresas familiares difere ou não das não familiar, constatando que as empresas familiares são mais endividadas do que as empresas não familiares. 
$\mathrm{Na}$ tabela 3 apresenta-se a regressão e análise do endividamento de curto prazo em relação a Estrutura de Gestão Familiar, conforme apresentado nas hipóteses e no constructo.

Tabela 3- Fatores associados ao endividamento de longo prazo

\begin{tabular}{|c|c|c|c|c|}
\hline Variáveis & Coeficiente & Erro padrão & Valor $\mathrm{t}$ & Valor $\mathrm{p}$ \\
\hline GF & -0.040 & 0.121 & -0.33 & 0.74 \\
\hline TM & -0.837 & 0.580 & -1.44 & 0.15 \\
\hline CUSTO_ENDIV & 0.473 & 0.208 & 2.27 & $0.02 * *$ \\
\hline CRESC & 0.354 & 0.146 & 2.42 & $0.02 * *$ \\
\hline CRESC_RECEITA & 0.002 & 1.670 & 0.10 & $0.00 * * *$ \\
\hline IDADE & -0.297 & 0.346 & -0.86 & 0.39 \\
\hline ROA & 0.000 & 0.001 & 0.51 & 0.61 \\
\hline Constante & 5.838 & 3.993 & 1.46 & 0.15 \\
\hline sigma_u & 3.305 & \multicolumn{2}{|c|}{ R2 Ajustado - within } & 0.09 \\
\hline sigma_e & 0.641 & \multicolumn{2}{|c|}{ R2 Ajustado -between } & 0.03 \\
\hline Rho & 0.964 & \multicolumn{2}{|c|}{ R2 Ajustado -overall } & 0.03 \\
\hline & & \multicolumn{2}{|c|}{ Valor da estatística F } & 0.000 \\
\hline
\end{tabular}

*significância ao nível de $10 \%$; ** significância ao nível de 5\%, e; ***significância ao nível de 1\%. As regressões foram estimadas a partir da técnica GLS. O modelo foi fundamentado a partir da seguinte equação:

$E L P_{i t}=\beta_{0}+\beta_{1} G F_{i t}+\beta_{2} T M_{i t}+\beta_{3} C U S T O_{-} E N D I V_{i t}+\beta_{4} C R E S C_{i t}+\beta_{5} C R E S C_{-} R E C E I T A_{i t}+\beta_{6} I D A D E_{i t}+\beta_{7} R_{O A}+$

$\varepsilon_{\text {it }}$

Fonte: Dados da pesquisa (2018)

Ao analisar o endividamento de longo prazo, observou-se aumento significativo do valor P em 0.74 na variável GF. A variável Custo de Endividamento ao nível de 5\% mostrou-se significante, evidenciando que quanto maior o endividamento de longo prazo maior a tendência de aumentar as despesas financeiras.

No que tange à variável Crescimento constata-se significância ao nível de 5\%, demonstrando que, quanto maior o crescimento dos ativos, mais as empresas familiares se endividam a longo prazo. No caso da variável Crescimento da Receita conta-se alto nível de significância (1\%). Em suma não se pode afirmar que a estrutura de gestão familiar (GF) está associada ao endividamento de longo prazo, já que esta variável estatisticamente não é significante. Os resultados convergem com Molly et al. (2018) que investigaram empresas familiares belgas e observaram a falta de associação positiva entre $O$ endividamento de longo prazo e a gestão familiar.

$\mathrm{Na}$ tabela 4 é apresentado a regressão em painéis do endividamento total de acordo as hipóteses apresentadas.

Tabela 4- Fatores associados ao Endividamento Total.

\begin{tabular}{|c|c|c|c|c|}
\hline Variáveis & Coeficiente & Erro padrão & Valor $\mathrm{t}$ & Valor p \\
\hline GF & 0.021 & 0.132 & 0.16 & 0.87 \\
\hline TM & -1.417 & 0.569 & -2.49 & $0.01 * *$ \\
\hline CUSTO_ENDIV & -0.132 & 0.301 & -0.44 & 0.66 \\
\hline CRESC & -0.325 & 0.180 & -1.80 & $0.07 *$ \\
\hline CRESC_RECEITA & 0.003 & -0.310 & 0.76 & $0.01 * *$ \\
\hline IDADE & -0.663 & 0.367 & -1.81 & $0.07 *$ \\
\hline ROA & -0.005 & 0.001 & -4.81 & $0.00 * * *$ \\
\hline Constante & 11.045 & 3.946 & 2.80 & 0.01 \\
\hline sigma_u & 3.282 & \multicolumn{2}{|c|}{ R2 Ajustado - within } & 0.32 \\
\hline sigma_e & 0.829 & \multicolumn{2}{|c|}{ R2 Ajustado -between } & 0.08 \\
\hline rho & 0.940 & \multicolumn{2}{|c|}{ R2 Ajustado -overall } & 0.10 \\
\hline & & \multicolumn{2}{|c|}{ Valor da estatística F } & 0.000 \\
\hline
\end{tabular}


*significância ao nível de $10 \%$; ** significância ao nível de 5\%, e; ***significância ao nível de 1\%. As regressões foram estimadas a partir da técnica GLS. O modelo foi fundamentado a partir da seguinte equação:

$E T_{i t}=\beta_{0}+\beta_{1} G F_{i t}+\beta_{2} T M_{i t}+\beta_{3} C U S T O \_E N D I V_{i t}+\beta_{4} C R E S C_{i t}+\beta_{5} C R E S C \_R E C E I T A_{i t}+\beta_{6} I D A D E_{i t}+\beta_{7} R O A_{i t}+\varepsilon_{i t}$

Fonte: Dados da pesquisa (2018)

Quando rodado com a variável Endividamento Total, observou-se aumento do R-quadrado, demonstrando que 32\% das variáveis independente explicam o ET. Para Cohen (1988) esse índice é considerado alto em ciências sociais aplicadas. Referente à variável tamanho, observou-se significância ao nível de 1\% demonstrando que quanto menor o tamanho da empresa familiar menor a tendência da empresa se endividar, quanto a variável crescimento (CRESC) constata-se uma significância ao nível de 10\%; na variável Crescimento da Receita o nível de significância foi de 5\% e ROA ao nível de 1\%, o que evidencia que quanto menor a relação entre o ativo total e patrimônio líquido, maior será as estrutura de capital de terceiros.

Diante das constatações pode-se observar que na primeira regressão apresentada, referente a estrutura de capital de curto prazo, a hipótese 1a (H1a) foi suportada pois foi possível identificar a nível de $10 \%$ de significância que a estrutura de gestão familiar está positivamente associada ao endividamento de curto prazo, ou seja, a estrutura de gestão familiar influência nas decisões de obtenção de capital de terceiros a curto prazo. Esses achados corroboram com Ampenberger et al. (2013), pois afirmam que a estrutura de Gestão Familiar tende a influenciar na maneira como se toma as decisões na organização, quanto a obtenção de capital de terceiros.

Depreende-se que as empresas familiares brasileira preferência obter financiamento de curto prazo ao considerar que sua atividade operacional será suficiente para honrar com seus compromissos. De outro lado, por se tratar de um modelo organizacional mais conservador que preza pelos valores da família, a tendência de contrair empréstimos de longo prazo que acarretam maiores incertezas é menor.

O estudo não comprovou as hipóteses (HIb e H1c), ou seja, embora exista alguma relação entre a estrutura de gestão familiar e a estrutura de capital, não foi possível estatisticamente demonstrar que o controle familiar influencia no endividamento total e na forma como a empresa se endivida a longo prazo, o que corrobora com os achados de Segura e Formigoni (2014), que afirmaram não haver associação estatisticamente significante entre as variáveis de controle familiar e o endividamento. Da mesma forma, Ramalho, Rita e Silva (2018), ao investigarem a influência da família na forma como as empresas se endividam, constataram que em fases de crise as empresas familiares tendem a possuir maior proporção de endividamento.

Um outro aspecto que poderia explicar a razão pela qual a variável Tamanho (TM) se mostrou significativa, é sustentada na observação de Ramalho, Rita e Silva (2018) quando afirmaram que a estrutura de capital de terceiros em empresas familiares varia de acordo com seu tamanho.

Observa-se que a não confirmação das hipóteses (HIb e H1c), permite inferir que as organizações familiares brasileiras, por serem mais conservadoras preferem desenvolver suas atividades com capital próprio. Pode-se com isso afirmar que diferente das empresas familiares no Paquistão conforme Yousaf e Hassan (2016) que preferem depender de capital de terceiras, as empresas familiares brasileiras de capital aberto são menos resistentes à mudança e por isso preferem emitir ações para extrair financiamento do mercado. 


\section{Considerações Finais}

O presente estudo buscou examinar a influência da estrutura de gestão familiar nomeadamente propriedade, controle e gestão familiar na estrutura de capital das empresas brasileiras de capital aberto. Para tanto selecionou-se empresas brasileiras listadas na B3 durante o período de 2013 a 2017, envolvendo uma amostra final de 266 empresas. Os dados referentes à estrutura de gestão familiar foram extraídos do formulário de referências e os dados contábeis foram obtidos da base de dados Economatica.

De acordo a definição de empresa familiar de Perez-Gonzalez (2006) contatou-se que 38\% da amostra de empresas da B3 eram classificadas como empresas familiares por apresentarem dois ou mais membros da mesma família na gestão, por possuírem dois ou mais fundadores da mesma família e por apresentarem participação acionária capaz de influenciar nas decisões do conselho de administração, bem como dois ou mais membros da mesma família como membros efetivos do conselho.

Conforme aos achados, pode-se concluir que as empresas familiares apresentam uma estrutura de capital de curto prazo maior do que as empresas não familiares, tendo vista que as ações dessas empresas são pouco diluídas, ou seja não são pulverizadas o suficiente para financiarem suas dívidas, logo recorrem a capital de terceiros para cumprirem com suas obrigações de curto prazo. Acredita-se que as empresas familiares por ser mais conservadoras e apresentarem maior aversão ao risco, seus proprietários tendem a não diluir suas participações a fim de evitar riscos aos seus poderes e continuarem a concentrar as decisões.

Observou-se ainda que quanto menor o Tamanho e a Idade da organização menor o endividamento de curto prazo, esse achado além de corroborar com Ramalho, Rita e Silva (2018) também demonstram que quando as empresas têm pouco tempo de experiência a tendência de recorrer ao endividamento é menor , do mesmo modo quanto ao tamanho se sua capacidade de gerar ativos é relativamente pequena, menor é a tendência ao endividamento. Por conseguinte, a medida em que a empresa vai se consolidando no mercado, adquirindo maior experiência, menor a dependência por capital de terceiros.

A falta de associação entre a estrutura de capital e o endividamento de longo prazo e total, pode sinalizar que as empresas familiares brasileiras, são menos dependentes de capital de terceiros, ou seja, preferem financiar suas atividades de longo prazo em geral, com recursos próprios. O período de análise dos dados foi de 2013 a 2017 uma época em que se constatou constante volatilidade tanto no mercado de ações quanto na própria economia do país, portanto acredita-se que esses fatores e não só tenham afetado nas preposições desse estudo quanto ao endividamento de longo prazo e total.

De maneira conclusiva, ao nível de significância de 10\% constatou-se uma associação positiva entre a estrutura de gestão familiar e endividamento a curto prazo. Ou seja, as empresas que possuem uma gestão familiar apresentam uma estrutura de capital de curto prazo maior do que as empresas não familiares, assim o estudo converge com os achados de Ampenberger et al. (2013).

Constatou-se ainda que a estrutura de gestão familiar não influencia no endividamento de longo prazo nem no endividamento total, significando que não há associação positiva entre o controle familiar e a estrutura de capital de terceiros de longo prazo e total corroborando com Segura e Formigoni (2014) quando ao verificarem a relação entre o controle familiar e o endividamento das empresas brasileiras de capital aberto durante o período de 2004 a 2009 concluíram que não houve uma relação estatisticamente significante.

O presente resultado encontra sustentação em Molly et al. (2018) quando, em pesquisa com empresas familiares belgas, constataram que a estrutura de gestão (centrada no objetivo ou representada no conselho de administração) afeta as decisões de endividamento de curto prazo com maior frequência do que as decisões da dívida de longo prazo. 
Esses achados geram implicações teóricas e práticas. Do ponto de vista teórico, o modelo organizacional que se investigou possui várias peculiaridade que podem gerar contribuições à literatura, por exemplo, Songini, Morelli e Vola (2018) afirmam que apesar de já existirem estudo que tratem sobre empresas familiares, no entanto é necessário mais pesquisa a fim de se perceber quais as implicações podem gerar ao campo de estudo.

Logo, pelo observado contribui-se para a literatura à medida em que se verificou que as empresas familiares brasileiras preferem obter capital de terceira apenas a curto prazo e que quando estão em fase inicial e possivelmente em tamanho menor geralmente não se endividam em razão do cenário organizacional. Contribui-se, portanto, com a teoria pecking order, dado que Myers e Majluf (1984) apontam que inicialmente as empresas usam recursos próprios e depois de se consolidarem recorrem a recursos externos. A cultura familiar muitas vezes determina a gestão. Pode-se perceber que quanto mais conservadora à família detentora do capital, menor é a tendência de obter empréstimos de longo prazo.

Do ponto de vista prático, o estudo gera implicações à gestão dessas empresas, por exemplo, empresas familiares geralmente são mais resistentes, logo os gestores dessas empresas precisam se atentar para diluição do capital, por meio de ações a fim de pulverizá-las e encontrar um equilíbrio.

Uma das limitações desse estudo consiste na definição que se tomou por base para classificar as empresas como familiares ou não, visto que não há unanimidade na literatura quanto à conceituação e definição de empresa familiar (SONFIELD;LUSSIER, 2012; RAMALHO; RITA; SILVA 2018). Por outro lado, não se pode generalizar as constatações desse estudo tendo em vista que foram analisadas apenas as empresas familiares de capital aberto, acredita-se que há um leque de empresas familiares de capital fechado que podem não se enquadrar nesses achados.

Sugere-se para próximas pesquisas um estudo de caso em duas empresas familiares, uma no início de seu ciclo de vida e outra no estágio de maturidade, objetivando entender, se em fase inicial as empresas familiares tendem a se endividar mais ou não e examinar as principais razões que as levam a recorrer a capital de terceiros, verificando as diferenças de acordo o ciclo de vida.

\section{Referências}

ANDERSON, Ronald C.; REEB, David M. Board composition: Balancing family influence in S\&P 500 firms. Administrative science quarterly, v. 49, n. 2, p. 209-237, 2004.

ASTRACHAN, Joseph H.; SHANKER, Melissa Carey. Family businesses' contribution to the US economy: A closer look. Family business review, v. 16, n. 3, p. 211-219, 2003.

BARONTINI, Roberto; CAPRIO, Lorenzo. The effect of family control on firm value and performance: Evidence from continental Europe. European Financial Management, v. 12, n. 5, p. 689-723, 2006.

BENAVIDES-VELASCO, Carlos A.; QUINTANA-GARCÍA, Cristina; GUZMÁN-PARRA, Vanesa F. Trends in family business research. Small business economics, v. 40, n. 1, p. 41-57, 2013.

BERRONE, Pascual; CRUZ, Cristina; GOMEZ-MEJIA, Luis R. Socioemotional wealth in family firms: Theoretical dimensions, assessment approaches, and agenda for future research. Family Business Review, v. 25, n. 3, p. 258-279, 2012.

BHALLA, Ajay; HENDERSON, Steven; WATKINS, David. A multiparadigmatic perspective of strategy: A case study of an ethnic family firm. International Small Business Journal, v. 24, n. 5, p. 515537, 2006. 
BLANCO-MAZAGATOS, Virginia; DE QUEVEDO-PUENTE, Esther; CASTRILLO, Luis A. The trade-off between financial resources and agency costs in the family business: An exploratory study. Family Business Review, v. 20, n. 3, p. 199-213, 2007.

BIRD, Barbara; BRUSH, Candida. A gendered perspective on organizational creation. Entrepreneurship theory and practice, v. 26, n. 3, p. 41-65, 2002.

CARNEY, Michael et al. What do we know about private family firms? A meta-analytical review. Entrepreneurship Theory and Practice, v. 39, n. 3, p. 513-544, 2015.

CHEN, Shuping; CHEN, Xia; CHENG, Qiang. Do family firms provide more or less voluntary disclosure?. Journal of accounting research, v. 46, n. 3, p. 499-536, 2008.

CLAESSENS, Stijn et al. Disentangling the incentive and entrenchment effects of large shareholdings. The journal of finance, v. 57, n. 6, p. 2741-2771, 2002.

COHEN, J. Statistical power analysis for the behaviors science.(2nd). New Jersey: Laurence Erlbaum Associates, Publishers, Hillsdale, 1988.

DENNIS JR, William J. Raising response rates in mail surveys of small business owners: Results of an experiment. Journal of Small Business Management, v. 41, n. 3, p. 278-295, 2003.

DIÉGUEZ-SOTO, Julio; LÓPEZ-DELGADO, Pilar. Does Family and Lone Founder Involvement Lead to Similar Indebtedness?. Journal of Small Business Management.

GERSICK, Kelin E. et al. Stages and transitions: Managing change in the family business. Family Business Review, v. 12, n. 4, p. 287-297, 1999.

FAVERO, L. P.; BELFIORE, P. Métodos Quantitativos com Stata: Procedimentos, Rotinas e Análises de Resultados. Elsevier Brasil, 2014.

GIL, Antônio Carlos. Metodologia científica. São Paulo, v. 3, 2002.

GOMEZ-MEJIA, Luis R.; LARRAZA-KINTANA, Martin; MAKRI, Marianna. The determinants of executive compensation in family-controlled public corporations. Academy of management journal, v. 46, n. 2, p. 226-237, 2003.

GONZÁLEZ, Maximiliano et al. Family firms and debt: Risk aversion versus risk of losing control. Journal of Business Research, v. 66, n. 11, p. 2308-2320, 2013.

HABBERSHON, Timothy G.; WILLIAMS, Mary L. A resource-based framework for assessing the strategic advantages of family firms. Family business review, v. 12, n. 1, p. 1-25, 1999.

HANDLER, Wendy C. Methodological issues and considerations in studying family businesses. Family business review, v. 2, n. 3, p. 257-276, 1989.

HERNÁNDEZ-LINARES, Remedios; SARKAR, Soumodip; COBO, Manuel J. Inspecting the Achilles heel: a quantitative analysis of 50 years of family business definitions. Scientometrics, v. 115, n. 2, p. 929$951,2018$. 
KELLERMANNS, Franz W. et al. An exploratory study of family member characteristics and involvement: Effects on entrepreneurial behavior in the family firm. Family Business Review, v. 21, n. 1, p. 1-14, 2008.

LEMMON, Michael L.; LINS, Karl V. Ownership structure, corporate governance, and firm value: Evidence from the East Asian financial crisis. The journal of finance, v. 58, n. 4, p. 1445-1468, 2003.

MAURY, Benjamin. Family ownership and firm performance: Empirical evidence from Western European corporations. Journal of Corporate Finance, v. 12, n. 2, p. 321-341, 2006.

MARTINS JUNIOR, Joaquim. Como escrever trabalhos de conclusão de curso: instruções para planejar e montar, desenvolver, concluir, redigir e apresentar trabalhos monográficos e artigos. Petrópolis, RJ: Vozes, 2008.

MCCONAUGHY, Daniel L. et al. Founding family controlled firms: Efficiency and value. Review of Financial economics, v. 7, n. 1, p. 1-19, 1998.

MILLER, Danny et al. Are family firms really superior performers?. Journal of corporate finance, v. 13, n. 5, p. 829-858, 2007.

MISHRA, Chandra S.; MCCONAUGHY, Daniel L. Founding family control and capital structure: The risk of loss of control and the aversion to debt. Entrepreneurship theory and practice, v. 23, n. 4, p. 5364, 1999.

MODIGLIANI, Franco; MILLER, Merton H. The cost of capital, corporation finance and the theory of investment. The American economic review, v. 48, n. 3, p. 261-297, 1958.

MOLLY, Vincent et al. Family-centered goals, family board representation, and debt financing. Small Business Economics, p. 1-18, 2018.

MOK, Henry MK; LAM, Kin; CHEUNG, Iris. Family control and return covariation in Hong Kong's common stocks. Journal of Business Finance \& Accounting, v. 19, n. 2, p. 277-293, 1992.

MYERS, Stewart C.; MAJLUF, Nicholas S. Corporate financing and investment decisions when firms have information that investors do not have. Journal of financial economics, v. 13, n. 2, p. 187-221, 1984.

PAMPLONA, Edgar; DAL MAGRO, Cristian; SILVA, Tarcísio. Estrutura de capital e desempenho econômico de empresas familiares do Brasil e de Portugal. Revista Portuguesa e Brasileira de Gestão, v. 16, n. 2, 2017.

PÉREZ-GONZÁLEZ, Francisco. Inherited control and firm performance. American Economic Review, v. 96, n. 5, p. 1559-1588, 2006.

PIEPER, Torsten M.; KLEIN, Sabine B. The bulleye: A systems approach to modeling family firms. Family Business Review, v. 20, n. 4, p. 301-319, 2007.

PRENCIPE, Annalisa; BAR-YOSEF, Sasson; DEKKER, Henri C. Accounting research in family firms: Theoretical and empirical challenges. European Accounting Review, v. 23, n. 3, p. 361-385, 2014.

RAMALHO, Joaquim JS; RITA, Rui MS; DA SILVA, Jacinto Vidigal. The impact of family ownership on capital structure of firms: Exploring the role of zero-leverage, size, location and the global financial crisis. International Small Business Journal, p. 0266242617753050, 2018. 
RICHARDSON, Roberto Jarry. Pós-Graduação-Metodologia-Pesquisa Social: Métodos e TécnicasMétodos Quantitativos e Qualitativos-Capitulo 5. Editora ATLAS SA-2015-São Paulo, 2017.

SEGURA, Liliane Cristina; FORMIGONI, Henrique. Influência do controle e da gestão familiar no endividamento das empresas abertas Brasileiras: um estudo quantitativo. Brazilian Business Review, v. 11, n. 6, p. 51, 2014.

SHANKER, Melissa Carey; ASTRACHAN, Joseph H. Myths and realities: Family businesses' contribution to the US economy-A framework for assessing family business statistics. family business review, v. 9, n. 2, p. 107-123, 1996.

SHYU, Jonchi. Family ownership and firm performance: evidence from Taiwanese firms. International Journal of Managerial Finance, v. 7, n. 4, p. 397-411, 2011.

SIRMON, David G.; HITT, Michael A. Managing resources: Linking unique resources, management, and wealth creation in family firms. Entrepreneurship theory and practice, v. 27, n. 4, p. 339-358, 2003.

SMITH, Brian F.; AMOAKO-ADU, Ben. Management succession and financial performance of family controlled firms. Journal of Corporate Finance, v. 5, n. 4, p. 341-368, 1999.

SONFIELD, Matthew C.; LUSSIER, Robert N. Gender in family business management: A multinational analysis. Journal of Family Business Management, v. 2, n.

SONGINI, Lucrezia; MORELLI, Chiara; VOLA, Paola. Managerial Control Systems in Family Business: State of the Art. In: Performance Measurement and Management Control: The Relevance of Performance Measurement and Management Control Research. Emerald Publishing Limited, 2018. p. 193-220.

VILLALONGA, Belen; AMIT, Raphael. Benefits and costs of control-enhancing mechanisms in US family firms. ECGI WP Series in Finance, v. 209, n. 247.216, 2006.

XI, Jing Melanie et al. Mapping the field of family business research: past trends and future directions. International Entrepreneurship and Management Journal, v. 11, n. 1, p. 113-132, 2015.

YOUSAF, Imran et al. Effect of family control on corporate financing decisions: A case of Pakistan. Pakistan Institute of Development Economics, 2016. 